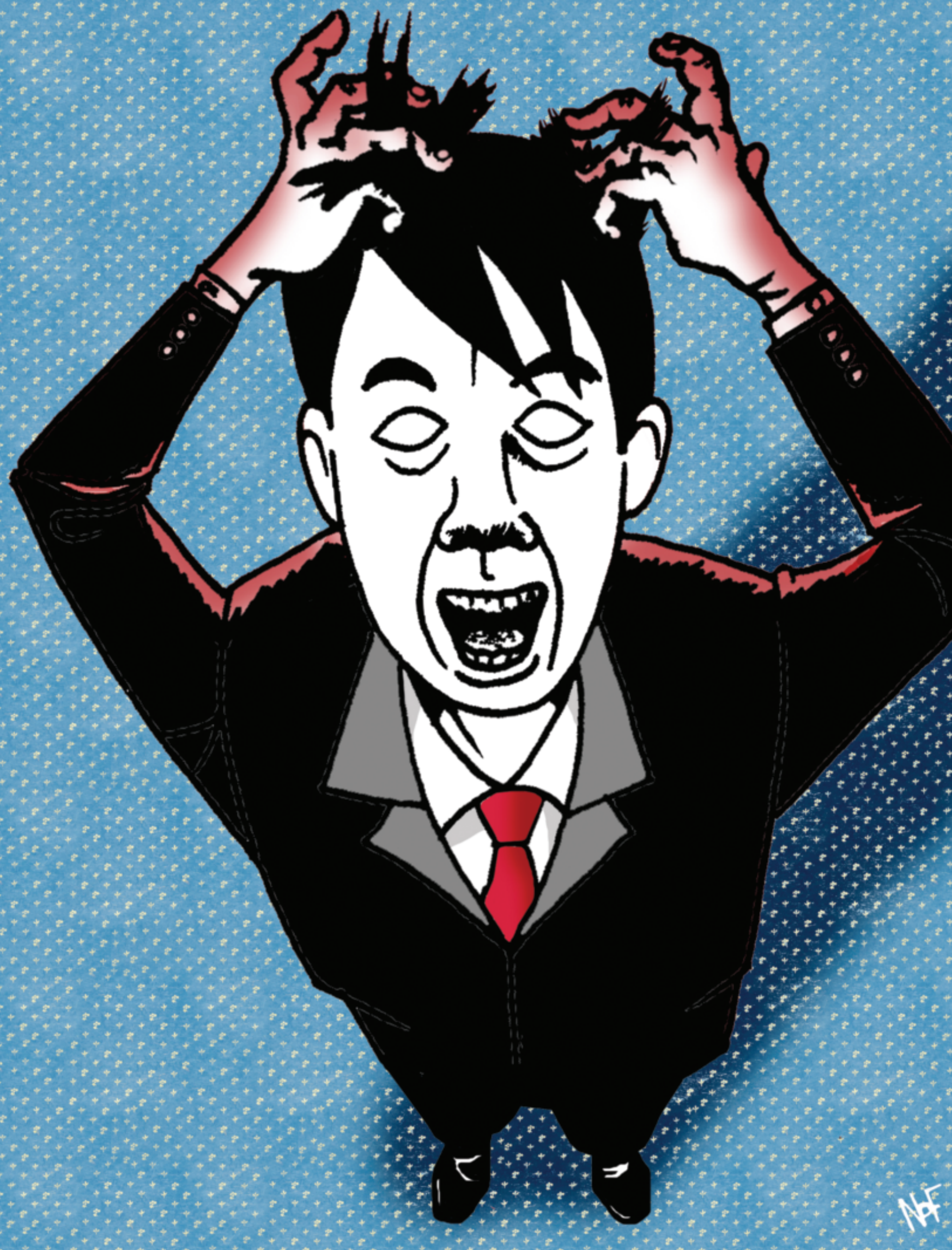




\section{El genoma humano \\ y las enfermedades \\ raras}

\section{Milton Jijón*}

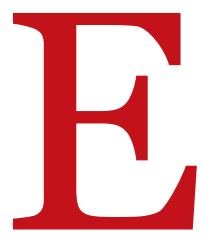

n junio 26 del año 2000, Bill Clinton y Tony Blair, entonces presidente y primer ministro de USA y Gran Bretaña, respectivamente, anunciaron el descubrimiento del genoma humano: los tres mil millones de pares de bases nitrogenadas (adenina - timina y guaninacitosina) que componen nuestro ADN. Se consideró el hecho más trascendente de la historia de la humanidad. El estudio del genoma humano se completó, sin embargo, solo en el año 2003. Su advenimiento transformó el curso de todas las ramas de las ciencias. Pero la biología, y particularmente la medicina, iban a sufrir descomunales cambios. La clonación, los seres transgénicos, el uso de células madre, los fármacos adaptados a los genes, la genética molecular, la paleogenómica son capítulos en vertiginoso avance, que van modificando la faz viviente del planeta. 
El descubrimiento del genoma humano permitió revelar la base genética de trastornos comunes como la hipertensión arterial o la diabetes. En el orden individual, estamos en condiciones de identificar la constitución de cada persona. Nos encontramos ad portas de la aplicación de la "medicina genómica personalizada”, que nos permitirá conocer los genes de cada hombre o mujer y "ver" su futuro clínico: qué enfermedades padecerá y, en consecuencia, cuáles se deben prevenir.

El siglo XXI ha sido denominado "La Centuria de la Genética”. Se avizora, en corto tiempo, la cura de enfermedades comunes aún no curables. Muchos trastornos, entre ellos el cáncer, serán vencidos merced al dominio de los genes que los producen. Se estima que, al disminuir las causas biológicas de muerte, los seres humanos vivirán saludablemente muchos años más. Se calcula que las generaciones de fines de siglo vivirán saludablemente más de 150 años. Los conceptos de adolescencia, tercera edad, madres añosas, tiempo de jubilación, por tanto, serán distintos de los que ahora manejamos.

El conocimiento del genoma de cada perso-

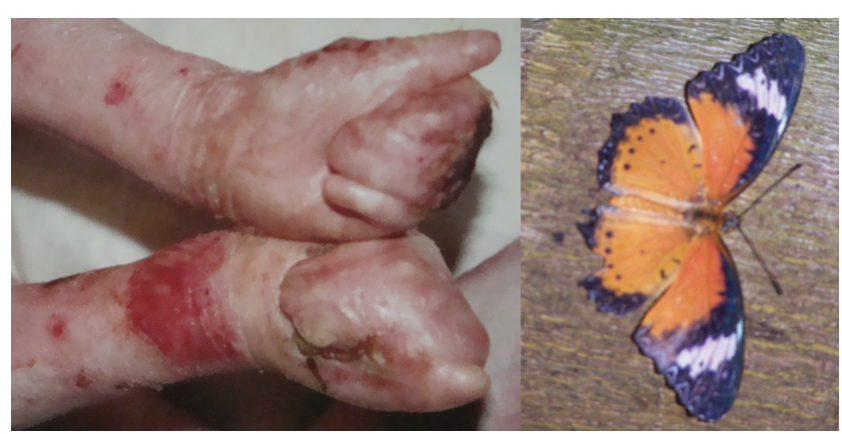

El "Síndrome Mariposa" o Epidermólisis Bollosa, es una enfermedad que padecen varias familias del Ecuador y para la cual no hay remedio específico. Fuente: Casuística personal, M. Jijón, 2010. momento, no se han considerado; sobre todo, en países como el nuestro.

Tras el descubrimiento del genoma humano, y para ir al ritmo de la medicina genómica y su inminente aplicación universal, grandes e innumerables proyectos han sido puestos en marcha. Wellcome Trust Case Control Consortium (WTCCC), en Inglaterra; KoraGen, en Alemania; CartaGene, en Australia; GAIN, Washington University Genome Sequencing; Broa Institute of MIT and Harvard, en USA; el Genome Institute en Francia. Estos proyectos, y otros más, se encargan de establecer las pautas para la aplicación de la medicina genómica personalizada.La cual no solo tiene que ver con las personas afectadas por enfermedades comunes. Hay un ámbito que representa un serio desafío científico, humano y socio-económico: las "Enfermedades Raras”.

Se llama así a un grupo compuesto por miles de trastornos graves, que pueden ocurrir en cualquier familia o individuo.

La mayoría de ellos son genéticos y de difícil diagnóstico. Son muy dolorosos y su impacto social es negativo. Se estima que el $8 \%$ de la población mundial sufre una enfermedad rara. Hasta la fecha, se han catalogado ocho mil enfermedades raras. Cada una de ellas afecta a un pequeño número de personas; pero, sumadas, son muchas. "Un mal de muchos es sufrir una enfermedad rara"; expresión patética que grafica el nivel de ocurrencia.

En Ecuador, no hay centros médicos para tratar las enfermedades raras ni una política oficial que permita cuantificar a los pacientes. El estudio genético-clínico de las discapacidades, reali-

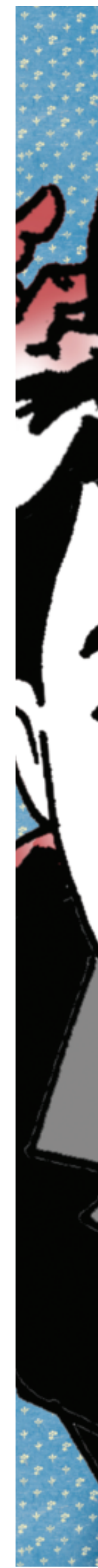


zado por la Misión Manuela Espejo, de la Vicepresidencia de la República, es el que más se ha acercado al problema. Por ello, la clasificación y difusión de sus resultados serán de sumo interés.

Hay organizaciones privadas destinadas a ayudar a pacientes con algunos de estos trastornos, por ejemplo, osteogénesis imperfecta, errores innatos de metabolismo, hemofilia, fibrosis quística del páncreas. Estos trastornos, genéticos y hereditarios, golpean reciamente a las familias en el campo médico y socio-económico. Sus costos son ingentes y, por lo general, impagables.

La instauración del Centro Nacional de Genética es urgente. Por varios años ha sido gestionado sin éxito por la Sociedad Ecuatoriana de Genética y sus miembros. Ellos, a través de centros privados y universitarios y a un pundonoroso esfuerzo, le han hecho frente a la adversa situación que sufren los miles de ecuatorianos afectados por enfermedades genéticas.

El único hospital público con servicio de genética clínica, el Baca Ortiz de Quito, ha instaurado y llevado adelante el tratamiento de síndromes genéticos y de enfermedades raras. Para hacerlo, ha aglutinado los esfuerzos multidisciplinarios del hospital así como el apoyo de organizaciones privadas sin fines de lucro. Pero esto no es ni será suficiente.

El advenimiento de la medicina genómica personalizada y la atención médica de las enfermedades raras son verdaderos retos a la salud pública de todos los países del mundo. La prescripción de los fármacos adaptados a los genes demanda una amplia y correcta información a la comunidad. De otra manera, se privará a los usuarios de ejercer sus derechos a una medicina que descubre sus más íntimas estructuras biológicas. 